\title{
A Simulation Study of the Direct Current Corrosion Characteristics of Carbon Steel Grounding Electrode with Ground Lead
}

\author{
Zhanlong Zhang ${ }^{1, *}$, Pan Gao ${ }^{1}$, Yihua Dan ${ }^{1}$, Guohua Liu ${ }^{2}$, Rui Xiang ${ }^{1}$, Jing Zou ${ }^{1}$ \\ ${ }^{1}$ State Key Laboratory of Power Transmission Equipment \& System Security and New Technology, \\ Chongqing University, Chongqing, 400030, China \\ ${ }^{2}$ Zhejiang Quzhou Power Supply Company of State Grid, Zhejiang, 324000, China) \\ *E-mail: zhanlongzhang@ 163.com
}

doi: $10.20964 / 2018.12 .42$

Received: 18 October 2017 / Accepted: 29 September 2018 / Published: 5 November 2018

\begin{abstract}
In this study, corrosion of the horizontal linear carbon steel grounding electrode buried in soil of the transmission system at various direct current (DC) densities was investigated by the electrode potential, $\mathrm{pH}$, anode iron dissolution and corrosion rate. A simulation model of DC corrosion behavior was established. The corrosion micro-mechanism of grounding electrode under DC interference was analyzed. This study found that the stray current density has a positive correlation with electrode potential, anode iron dissolution and corrosion rate. The DC current will significantly accelerate the dissolution rate and corrosion rate of the steel. The DC density has a different influence on the soil $\mathrm{pH}$ around the grounding electrode.
\end{abstract}

Keywords: Grounding electrode; Corrosion; Stray current; Simulation

\section{$\underline{\text { FULL TEXT }}$}

(C) 2017 The Authors. Published by ESG (www.electrochemsci.org). This article is an open access article distributed under the terms and conditions of the Creative Commons Attribution license (http://creativecommons.org/licenses/by/4.0/). 